\title{
Coach Education and Positive Youth Development as a Means of Improving Australian Sport
}

\author{
Jaimee E. Bateman ${ }^{1 *}$, Geoff P. Lovell ${ }^{2,3}$, Karena J. Burke ${ }^{1}$ and Michele Lastella ${ }^{4}$ \\ ${ }^{1}$ School of Health, Medical and Applied Sciences, Central Queensland University, Rockhampton, QLD, Australia, \\ ${ }^{2}$ Department of Sport, Hartpury University, Hartpury, United Kingdom, ${ }^{3}$ School of Health and Behavioural Sciences, \\ University of the Sunshine Coast, Sunshine Coast, QLD, Australia, ${ }^{4}$ School of Health, Medical and Applied Sciences, \\ Appleton Institute for Behavioural Science, Central Queensland University, Adelaide, SA, Australia
}

Keywords: positive youth development, coaching education, Australian youth sport, youth athlete development, youth sport coaches

\section{INTRODUCTION}

Sport plays a large role in Australian culture (Light, 2010) with over 90\% of Australians involved in playing or watching sport (Australian Sports Commission, 2017). However, retention of Australian athletes is at risk (Australian Sports Commission, 2017). Protecting Australian sport from decreased participation across all ages is vital to maintaining the intergenerational cycle of Australians playing sport (Australian Sports Commission, 2017). Sport is important to Australians' mental and physical health and contributes substantially to the economy (Australian Sports Commission, 2017). To address the prospect of declining participation, the Australian Sports Commission (2017) has declared a focus toward increasing youth athlete participation by the year 2036.

The objective of this paper is to suggest that Australian sport coaches, are vital in sustaining Australian youth sport participation (Duda, 1996; Cote and Mallett, 2012; Vella et al., 2013). Through coach education, coaches have the potential to enhance motivational climates that foster positive youth development (Duda, 1996; Falcao et al., 2012; Bailey et al., 2013; Santos et al., 2017). Positive youth development through sport occurs when young athletes obtain personal, physical and social skills from playing sport, that can be transferred to other areas of their lives; improving their present and future well-being and societal contributions (Holt et al., 2016).

Positive youth development through sport has been shown to increase participant retention (Smith and Smoll, 1997; Cote et al., 2010), due to enhancing athletes' general well-being (Roth and Brooks-Gunn, 2003; Falcao et al., 2012) and consequently boosting their enjoyment of sport. However, research on positive youth development in Australian sport is lacking (Light, 2010; Gould, 2016). More Australian studies are required to investigate if current coach education is adequate in providing coaches with knowledge and skills to foster positive youth development. Thus, this paper will conclude with research recommendations aimed at advancing our understanding of the effectiveness of Australian coaches and Australian coach education in promoting positive youth development through sport.

\section{MOTIVATIONAL REQUIREMENTS FOR POSITIVE YOUTH DEVELOPMENT}

Positive youth development occurs when children's values, beliefs and life-skills are proactively strengthened to enable maturation into well-balanced, optimal-functioning individuals 
(Gould and Carson, 2008). For positive youth development to occur, attention must be given to the motivational climate surrounding young people (Dweck, 1986; Bailey et al., 2013). The motivational climate is created through the way that influential adults define success; consequently, shaping how children interpret their efforts toward achieving goals (Dweck, 1986).

Two types of motivational climates have been identified; mastery and performance (Duda, 1996). In mastery-orientated environments, rather than emphasizing goal attainment, success is interpreted as self-improvement obtained when working toward one's goals (Duda, 1996). Focusing on the enjoyment and satisfaction of progress, especially through challenges and overcoming failures, teaches individuals social-emotional skills such as self-determination, work ethic and citizenship (Dweck, 1986). In contrast, performance-orientated environments can be detrimental to personal growth as they emphasize social comparisons and superior outcomes over others, with goal attainment the definition of success (Dweck, 1986). Performanceorientated individuals often seek easy pathways to achievement so as to avoid failure and social judgements, but in the process prevent themselves from developing social-emotional skills and satisfaction in the progress made toward goal attainment (Duda, 1996).

\section{FOSTERING POSITIVE YOUTH DEVELOPMENT THROUGH SPORT}

Sport is often considered training for real-life (Petitpas et al., 2005) and ideal for enhancing youth's positive development (Vella et al., 2011; Camire, 2015). Positive youth development through sport goes beyond building athletes' sport specific abilities, and aims to cultivate their psychological, social, emotional, physical and intellectual skills (Roth and BrooksGunn, 2003; Cote et al., 2010; Santos et al., 2017) that can be utilized in sport and life (Gould and Carson, 2008; Falcao et al., 2012). Mastery-orientated contexts that deemphasize the outcome of winning and prioritize athletes' self-improvement in abilities and sportsmanship (Duda, 1996; Roth and Brooks-Gunn, 2003; Bailey et al., 2013), have been reported as necessary for positive youth development through sport (Cote and Mallett, 2012). Mastery-orientated sports provide athletes with opportunities to experience challenges, independence and cooperation; all while athletes' efforts are supported and encouraged (Dweck, 1986; Ames and Archer, 1988; Bailey et al., 2013). Athletes who feel safe and supported in taking risks toward reaching goals, regardless of the outcome, are more likely to engage in activities that foster their cognitive and social-emotional skills (Duda, 1996; Falcao et al., 2012; Vella et al., 2013). The support, enjoyment and positive development experienced in masteryorientated sports, as well as increased overall well-being (Roth and Brooks-Gunn, 2003; Camire and Trudel, 2014), reinforces athletes' desire to remain playing sport (Ames and Archer, 1988; Cote and Mallett, 2012; Bailey et al., 2013).

\section{THE IMPORTANCE OF COACHES}

In the context of sport, youth coaches are considered teachers and leaders (Feltz et al., 1999). Parents, athletes and sporting organizations entrust coaches to help athletes develop, both in and out of the sporting arena (Camire, 2015; Strachan et al., 2016). As the primary influences on the sporting climate (Ames and Archer, 1988; Duda, 1996; Bailey et al., 2013), coaches are pivotal in fostering positive youth development through sport (Cote et al., 2010; Camire et al., 2012; Vella et al., 2013). When coaches deliberately create mastery-orientated environments that aim to develop athletes beyond sporting skills and tactics, positive youth development becomes more likely (Holt et al., 2017). Creating a mastery-orientated environment conducive to positive youth development, requires coaches emphasize the goal of sport as being to learn from mistakes while enjoying working hard for personal improvement (Duda, 1996). Coaches should focus on athletes' development rather than performance, with athletes evaluated against themselves, not others (Ames and Archer, 1988). It is vital that coaches make all athletes feel important and acknowledged (Dweck, 1986). Coaches can further encourage athletes' positive development by incorporating deliberate lessons into their programs, designed to teach life-skills (Gould and Carson, 2008; Holt et al., 2017) such as emotional control (Falcao et al., 2012), cultural competence, personal responsibility, and interpersonal skills (Light, 2010; Camire et al., 2012). Finally, improving youth athletes' positive development can be achieved through coaching behaviors such as role modeling, fostering strong relationships, using empathetic communication (Smith and Smoll, 1997), and positive reinforcement (Gould et al., 1989).

\section{PROBLEMS WITH POSITIVE YOUTH DEVELOPMENT THROUGH SPORT}

Athlete development through sport is, unfortunately, not always positive (Shields and Bredemeier, 2010). Just as coaches shape mastery-orientated environments, they also influence performance-orientated athletes (Duda, 1996), possibly due to cultural norms of winning at all costs (Cote and Mallett, 2012). Currently, youth sports in Australia are predominantly performance-driven (Cote and Mallett, 2012; Agnew et al., 2016). Athletes who participate in performance-driven sports are more likely to develop negatively (Cote et al., 2010) and experience increased adversity in (Camire et al., 2012) and out of sport (Gould and Carson, 2008). In their report to the Australian Sports Commission, Cote and Mallett (2012) suggested that athlete attrition in Australian youth sports may be attributed to the performance-driven sporting culture and its lack of emphasis on positive youth development.

Most coaches understand that they can inspire positive youth development (Gould et al., 2006; Vella et al., 2011, 2013; Santos et al., 2017); however, preliminary data suggests they do not fully understand why (Bean and Forneris, 2017). Many coaches do not actively foster positive youth development in athletes, believing positive development occurs through participation 
alone (Bean and Forneris, 2017). Other coaches take a reactive approach, only addressing personal development if problems occur (Zakrajsek and Zizzi, 2008). Coaches who do aim to incorporate positive youth development, often use limited positive youth development methods (Gould et al., 1989) or inadvertently employ approaches that negatively impact youth development (Dweck, 1986; McCallister et al., 2000).

A lack of education on positive youth development in sport (Erickson et al., 2008; Harwood, 2008; Santos et al., 2017) may attribute to coaching mistakes and limitations (Lerner et al., 2005; Strachan et al., 2016) that negatively influence athletes (Petitpas et al., 2005; Cote et al., 2010; Vella et al., 2013). Positive youth development coach education programs help coaches develop confidence (Falcao et al., 2012; Santos et al., 2017), self-awareness (Smith and Smoll, 1997) and knowledge (Vella et al., 2013) in fostering positive development in athletes. Despite the advantages of educating coaches on positive youth development, most compulsory coach education courses focus primarily on sporting skills and tactics (Santos et al., 2017). Little importance is given in coach education to the holistic development of athletes, especially at the community level (Wiersma and Sherman, 2005).

\section{THE NEED FOR MANDATORY POSITIVE YOUTH DEVELOPMENT COACH EDUCATION}

International research provides a strong argument for the mandatory inclusion of positive youth development components in Australian coach education (Erickson et al., 2008; Harwood, 2008; Falcao et al., 2012; Strachan et al., 2016). For example, without being part of mandatory education, positive youth development in sport is devalued (Harwood, 2008; Falcao et al., 2012; Strachan et al., 2016) and difficult for coaches to source (Erickson et al., 2008; Strachan et al., 2016). Positive youth development education programs are available online, however most coaches are unaware of their existence (Nash and Sproule, 2012).

Introducing mandatory positive youth development education would ensure all Australian coaches are aware of the importance of positive youth development in sport (Harwood, 2008) and equipped with the knowledge, confidence and skills to foster positive development in larger populations of athletes (Falcao et al., 2012). Larger numbers of positively developed athletes will increase sport participation rates (Cote and Mallett, 2012), athletes' longevity in sport (Camire et al., 2012), individual contributions to society (Lerner et al., 2005), sporting organisations' sustainability, and the Australian economy (Australian Sports Commission, 2017). Therefore, coach education that includes positive youth development education, not just sport specific information, will help coaches create mastery-orientated sporting environments that enable youth to develop into healthy, functioning adults with less destructive behaviors, improved civic engagement (Lerner et al., 2005) and sustained sports participation (Duda, 1996). Successful integration of positive youth development coach education into Australian youth sport will require the collaboration of governing sporting bodies, policymakers, education providers, coaches, sporting clubs, and parents (Camire, 2015; Australian Sports Commission, 2017).

\section{SHORTFALLS IN AUSTRALIAN RESEARCH}

Positive youth development has been studied from various theoretical perspectives including motivation theory, selfdetermination theory, social learning theory and ecological systems theory (Lerner et al., 2005; Weiss, 2016), however few real-world applications have resulted (Weiss, 2016). To date there has been a lack of large-scale research on positive youth development in Australian sport to support claims that increasing coach education on positive youth development will actually benefit Australian sport (Light, 2010; Vella et al., 2011). There is currently little research within the Australian context to answer the following pertinent questions:

- Is there concordance between what Australian coaches should know and practice regarding positive youth development in sport and what they actually do understand and apply (Bailey et al., 2013)?

- Do Australian coaches have efficient access to quality positive youth development coach education (Nash and Sproule, 2012; Bailey et al., 2013; Pope et al., 2015) that has been empirically tested for Australian youth sporting populations (Conroy and Coatsworth, 2006; Gould, 2016)?

- What opinions and knowledge do Australian coaches and parents have about coach education and positive youth development in sport (Wiersma and Sherman, 2005; VargasTonsing, 2007; Bailey et al., 2013; Camire and Trudel, 2014; Newman et al., 2016; Santos et al., 2017)?

- What cultural impacts and individual beliefs influence positive youth development in Australian sport (Bailey et al., 2013)?

\section{CONCLUSION}

The objective of this paper was to stress the important role of coach education in providing coaches with information on creating mastery-orientated environments that foster positive youth development. Past research indicates that positive youth development through sport benefits individual athletes, coaches, families, sporting organizations, and communities. The diverse benefits of positive youth development through sport, suggest that enhancing positive youth development in Australian sport through improved, mandatory coach education may have profound consequences, including sustained youth athlete participation. However, more research is needed to determine if international findings are relevant for Australian sport and to further understand how positive youth development can be fostered through Australian sport to benefit everyone involved. 


\section{AUTHOR CONTRIBUTIONS}

JB conceived the original idea for the commentary and drafted the article. ML oversaw the project and offered advice on

\section{REFERENCES}

Agnew, D., Pill, S., and Drummond, M. (2016). Investigating the elements that encourage or inhibit the participation of children and youth in Australian Football. Ann. Leis. Res. 19, 27-46. doi: 10.1080/11745398.2015.10 36898

Ames, C., and Archer, J. (1988). Achievement goals in the classroom: students' learning strategies and motivation processes. J. Educ. Psychol. 80, 260-267. doi: 10.1037/0022-0663.80.3.260

Australian Sports Commission. (2017). Intergenerational Review of Australian Sport 2017. Available online at: https://www.sportaus.gov.au/_data/assets/ pdf_file/0011/660395/Intergenerational_Review_of_Australian_Sport_2017. pdf (accessed July 20, 2020).

Bailey, R., Cope, E. J., and Pearce, G. (2013). Why do children take part in, and remain involved in sport? A literature review and discussion of implications for sports coaches. Int. J. Coach. Sci 7, 55-74.

Bean, C., and Forneris, T. (2017). Is life skill development a by-product of sport participation? Perceptions of youth sport coaches. J. Appl. Sport Psychol. 29, 234-250. doi: 10.1080/10413200.2016.1231723

Camire, M. (2015). Reconciling competition and positive youth development in sport. Straps 3, 25-39. doi: 10.3917/sta.109.0025

Camire, M., and Trudel, P. (2014). Helping youth sport coaches integrate psychological skills in their coaching practice. Quali. Res. Sport. Exerc. Health. 6, 617-634. doi: 10.1080/2159676X.2013.841281

Camire, M., Trudel, P., and Forneris, T. (2012). Coaching and transferring life skills: philosophies and strategies used by model high school coaches. Sport Psychol. 26, 243-260. doi: 10.1123/tsp.26.2.243

Conroy, D. E., and Coatsworth, J. D. (2006). Coach training as a strategy for promoting youth social development. Sport Psychol. 20, 128-144. doi: $10.1123 /$ tsp.20.2.128

Cote, J., Bruner, M., Erickson, K., Strachan, L., and Fraser-Thomas, J. (2010). "Athlete development and coaching," in Sports Coaching: Professionalisation and Practice, eds J. Lyle, and C. Cushion (Churchill Livingstone Elsevier), 63-84.

Cote, J., and Mallett, C. J. (2012). Review of Junior Sport Framework Draft Briefing Paper: Positive Youth Development Through Sport (Project No. 715). St. Lucia: Australian Sports Commission.

Duda, J. L. (1996). Maximising motivation in sport and physical education among children and adolescents: the case for greater task involvement. Quest 48, 290-302. doi: 10.1080/00336297.1996.10484198

Dweck, C. S. (1986). Motivational processes affecting learning. Am. Psychol. 41, 1040-1048. doi: 10.1037/0003-066X.41.10.1040

Erickson, K., Bruner, M. W., MacDonald, D. J., and Cote, J. (2008). Gaining insight into actual and preferred sources of coaching knowledge. Int. J. Sports Sci. Coach. 3, 526-538. doi: 10.1260/174795408787186468

Falcao, W. R., Bloom, G. A., and Gilbert, W. D. (2012). Coaches' perceptions of a coach training program designed to promote youth developmental outcomes. J. Appl. Sport Psychol. 24, 429-444. doi: 10.1080/10413200.2012. 692452

Feltz, D. L., Chase, M. A., Moritz, S., and Sullivan, P. J. (1999). A conceptual model of coaching efficacy: Preliminary investigation and instrument development. J. Educ. Psychol. 91, 765-776. doi: 10.1037/0022-0663.91.4.765

Gould, D. (2016). Conducting impactful coaching science research: The forgotten role of Knowledge integration and dissemination. Int. Sport Coach. J. 3, 197-203. doi: 10.1123/iscj.2015-0113

Gould, D., and Carson, S. (2008). Life skills development through sport: current status and future directions. Int. Rev. Sport Exerc. Psychol. 1, 58-78. doi: 10.1080/17509840701834573

Gould, D., Chung, Y., Smith, P., and White, J. (2006). Future directions in coaching life skills: Understanding high school coaches' views and needs. Athl. Insight $8,28-38$. direction for the paper. ML, GL, and $\mathrm{KB}$ critically revised the paper and contributed ideas to the final article. ML gave final approval. All authors contributed to the article and approved the submitted version.
Gould, D., Hodge, K., Peterson, K., and Giannini, J. (1989). An exploratory examination of strategies used by elite coaches to enhance self-efficacy in athletes. J. Sport Exerc. Psychol. 11, 128-140. doi: 10.1123/jsep.11.2.128

Harwood, C. (2008). Developmental consulting in a professional football academy: the 5Cs coaching efficacy program. Sport Psychol. 22, 109-133. doi: $10.1123 /$ tsp.22.1.109

Holt, N. L., Deal,. C. J., and Smyth, C. L. (2016). "Future directions for positive youth development through sport," in Positive Youth Development Through Sport, 2nd Edn, eds N. L. Holt (Routledge), 83-96.

Holt, N. L., Neely, K. C., Slater, L. G., Camire, M., Cote, J., Fraser-Thomas, J., et al. (2017). A grounded theory of positive youth development through sport based on results from a qualitative meta-study. Int. Rev. Sport Exerc. Psychol. 10, 1-49. doi: 10.1080/1750984X.2016.1180704

Lerner, R. M., Lerner, J. V., Almerigi, J. B., Theokas, C., Phelps, E., Gestsdottir, S., et al. (2005). Positive youth development, participation in community youth development programs, and community contributions of fifth-grade adolescents: findings from the first wave of the $4-\mathrm{H}$ study of positive youth development. J. Early Adolesc. 25, 17-71. doi: 10.1177/0272431604272461

Light, R. L. (2010). Children's social and personal development through sport: a case study of an Australian swimming club. J. Sport Soc. Issu. 34, 379-395. doi: 10.1177/0193723510383848

McCallister, S. G., Blinde, E. M., and Weiss, W. M. (2000). Teaching values and implementing philosophies: Dilemmas of the youth sport coach. Phys. Educat. 57, 35-44. Available online at: https://js.sagamorepub.com/pe/article/ view/2249

Nash, C., and Sproule, J. (2012). Coaches perceptions of their coach education experiences. Int. J. Sport Psychol. 43, 33-52. doi: 10.7352/IJSP.2012.43.033

Newman, T. J., Ortega, R. M., Lower, L. M., and Paluta, M. (2016). Informing priorities for coaching education: Perspectives from youth sport leaders. Int. J. Sports Sci. Coach. 11, 422-435. doi: 10.1177/1747954116645207

Petitpas, A. J., Cornelius, A. E., Van Raalte, J. L., and Jones, T. (2005). A framework for planning youth sport programs that foster psychosocial development. Sport Psychol. 19, 63-80. doi: 10.1123/tsp.19.1.63

Pope, J. P., Stewart, N. W., Law, B., Hall, C. R., Gregg, M. J., and Robertson, R. (2015). Knowledge translation of sport psychology to coaches: coaches' use of online resources. Int. J. Sports Sci. Coach. 10, 1055-1070. doi: 10.1260/1747-9541.10.6.1055

Roth, J. L., and Brooks-Gunn,. J. (2003). What exactly is a youth development program? Answers from research and practice. Appl. Dev. Sci. 7, 94-111. doi: 10.1207/S1532480XADS0702_6

Santos, F., Camire, M., MacDonald, D. J., Campos, H., Conceicao, M., and Silva, P. (2017). Youth sport coaches' perspective on positive youth development and its worth in mainstream coach education courses. Int. Sport Coach. J. 4, 38-46. doi: 10.1123/iscj.2016-0092

Shields, D. L., and Bredemeier, B. L. (2010). Competition: Was Kohn right? Phi Delta Kappan. 91, 62-67. doi: 10.1177/003172171009100516

Smith, R. E., and Smoll, F. L. (1997). Coaching the coaches: youth sports as a scientific and applied behavioral setting. Curr. Dir. Psychol. Sci. 6, 16-21. doi: 10.1111/1467-8721.ep11512606

Strachan, L., MacDonald, D. J., and Côt,é, J. (2016). Project SCORE! Coaches' perceptions of an online tool to promote positive youth development in sport. Int. J. Sports Sci. Coach. 11, 108-115. doi: 10.1177/17479541156 24827

Vargas-Tonsing, T. M. (2007). Coaches' preferences for continuing coaching education. Int. J. Sports Sci. Coach. 2, 25-35. doi: 10.1260/1747954077803 67186

Vella, S., Oades, L., and Crowe, T. (2011). The role of the coach in facilitating positive youth development: Moving from theory to practice. J. Appl. Sport Psychol. 23, 33-48. doi: 10.1080/10413200.2010.511423

Vella, S., Oades, L., and Crowe, T. (2013). A pilot test of transformational leadership training for sports coaches: Impact on the developmental 
experiences of adolescent athletes. Int. J. Sports Sci. Coach. 8, 513-530. doi: 10.1260/1747-9541.8.3.513

Weiss, M. R. (2016). "Old wine in a new bottle: historical reflections on sport as a context of youth development," in Positive Youth Development Through Sport, 2nd Edn, eds N. L. Hold (Routledge), 7-20.

Wiersma, L. D., and Sherman, C. P. (2005). Volunteer youth sport coaches' perspectives of coaching education/certification and parental codes of conduct. Res. Q. Exerc. Sport 76, 324-338. doi: 10.1080/02701367.2005.10599303

Zakrajsek, R. A., and Zizzi, S. J. (2008). How do coaches' attitudes change when exposed to a sport psychology workshop? J. Coach. Educ. 1, 66-83. doi: $10.1123 /$ jce.1.1.66
Conflict of Interest: The authors declare that the research was conducted in the absence of any commercial or financial relationships that could be construed as a potential conflict of interest.

Copyright $\odot 2020$ Bateman, Lovell, Burke and Lastella. This is an open-access article distributed under the terms of the Creative Commons Attribution License (CC BY). The use, distribution or reproduction in other forums is permitted, provided the original author(s) and the copyright owner(s) are credited and that the original publication in this journal is cited, in accordance with accepted academic practice. No use, distribution or reproduction is permitted which does not comply with these terms. 